\title{
Abundances of Planetary Nebulae IC 418, IC 2165 and NGC 5882
}

\author{
S. R. Pottasch ${ }^{1}$, J. Bernard-Salas ${ }^{1,2,3}$, D. A. Beintema ${ }^{1,2}$, and W. A. Feibelman ${ }^{3}$ \\ 1 Kapteyn Astronomical Institute, PO Box 800, 9700 AV Groningen, The Netherlands \\ e-mail: pottasch@astro.rug.nl \\ 2 SRON Laboratory for Space Research, PO Box 800, 9700 AV Groningen, The Netherlands \\ 3 Center for Radiophysics and Space Research, Cornell University, 219 Space Sciences Building, \\ Ithaca, NY-14850-6801, USA \\ ${ }^{4}$ Laboratory for Astronomy and Solar Physics, Code 681, Goddard Space Flight Center, MD, USA
}

Received 9 March 2004 / Accepted 14 May 2004

\begin{abstract}
The ISO and IUE spectra of the elliptical nebulae NGC 5882, IC 418 and IC 2165 are presented. These spectra are combined with the spectra in the visual wavelength region to obtain a complete, extinction corrected, spectrum. The chemical composition of the nebulae is then calculated and compared to previous determinations. A discussion is given of: (1) the recombination line abundances; (2) the exciting stars of the nebulae; and (3) possible evolutionary effects.
\end{abstract}

Key words. ISM: abundances - ISM: planetary nebulae: individual: NGC 5882; IC 418; IC 2165 - infrared: ISM

\section{Introduction}

IC 418, IC 2165 and NGC 5882 are morphologically quite similar; they are usually classified as elliptical in shape, and they are located rather far from the galactic plane, which is probably an indication that they have been formed from low mass stars. They are all reasonably small nebulae on the sky, i.e. most of their emission comes from a small diameter. IC 2165 has a circular shape with a diameter of $8^{\prime \prime}$. It is surrounded by two haloes (Corradi et al. 2003) but these have very little emission compared to the nebula itself. IC 418 is slightly larger, elliptical in shape, with a size of about $14^{\prime \prime} \times 12^{\prime \prime}$. It too is surrounded by a low level ionized halo, which in turn is surrounded by a region of neutral hydrogen which has a diameter of about $2^{\prime}$ (Taylor et al. 1989). Finally NGC 5882 is more or less circular with a diameter of about 13-14"; it contains several distinctive clumps of ionized material. It is also surrounded by low level emission which extends about three times as far (Guerrero \& Manchado 1999), but it is less well studied than the other two nebulae.It is possible to define an axis of symmetry for all of these nebulae.

The purpose of this paper is to study the element abundances in these nebulae with the help of the mid-infrared ISO spectra. Abundances in all three nebulae have been studied for many years already, but the inclusion of the ISO spectra permits a more accurate determination. The reasons for this have

* Based on observations with ISO, an ESA project with instruments funded by ESA Member States (especially the PI countries: France, Germany, The Netherlands and the United Kingdom) and with the participation of ISAS and NASA. been discussed in earlier papers (e.g. see Pottasch \& Beintema 1999; Pottasch et al. 2000, 2001; Bernard Salas et al. 2001), and can be summarized as follows.

The most important advantage is that the infrared lines originate from very low energy levels and thus give an abundance which is not sensitive to the temperature in the nebula, nor to possible temperature fluctuations. Furthermore, when a line originating from a high-lying energy level in the same ion is observed, it is possible to determine an effective temperature at which the lines in that particular ion are formed. When the effective temperature for many ions can be determined, it is possible to make a plot of effective temperature against ionization potential, which can be used to determine the effective temperature for ions for which only lines originating from a high energy level are observed. Use of an effective electron temperature takes into account the fact that ions are formed in different regions of the nebula. At the same time possible temperature fluctuations are taken into account.

Use of the ISO spectra have further advantages. One of them is that the number of observed ions used in the abundance analysis is approximately doubled, which removes the need for using large "Ionization Correction Factors", thus substantially lowering the uncertainty in the abundance. A further advantage is that the extinction in the infrared is almost negligible, eliminating the need to include large correction factors.

These advantages lead to different abundances for some of the elements when compared with earlier determinations. These can be a factor of two different from earlier determinations and occasionally they differ by an order of magnitude. 
But sometimes they agree quite well with earlier work. For these three nebulae comparisons are shown in this paper.

The ISO diaphragm is able to measure essentially the entire nebula in both the shortward and longward wavelength region. This is more obvious in the ISO LWS spectra (which cover a spectral region from $45 \mu \mathrm{m}$ until almost $200 \mu \mathrm{m}$ ), since these spectra are taken with a diaphragm with a diameter of about $80^{\prime \prime}$. The ISO SWS spectra, covering the spectral region from $2.4 \mu \mathrm{m}$ to about $45 \mu \mathrm{m}$, are taken with a smaller diaphragm, but the diaphragm is still large enough to measure almost all of the nebular emission. We demonstrate this below when comparing the hydrogen line intensities measured with the SWS with the $\mathrm{H} \beta$ emission deduced from the radio continuum flux density.

This paper is structured as follows. First the ISO spectrum of the three nebulae is presented and discussed (in Sect. 22), together with the $6 \mathrm{~cm}$ radio continuum flux density. Section 3 discusses the visible spectrum of these nebulae, while Sect. 4 presents the ultraviolet (IUE) spectrum. This is followed by a discussion of the nebular electron temperature and density (Sect. 5) and the chemical composition of the three nebulae (Sect. 6). A comparison of the resultant abundances with those made earlier is given in Sect. 7. In this section the relation between nebular carbon abundances determined from collisionally excited lines and from recombination lines is also studied. In Sect. 8 the central stars are considered in more detail. Finally Sect. 9 gives a comparison with the abundances determined in other PN, and a general discussion.

\section{The ISO spectra}

\subsection{ISO observations of IC 418}

The ISO SWS observations were made with the SWS01 observing template which observes the entire range from $2.5 \mu \mathrm{m}$ to $45 \mu \mathrm{m}$ (TDT 82901301). The longwave observations were made with an LWS01 observation which covers the range from $45 \mu \mathrm{m}$ to $190 \mu \mathrm{m}$. The intensity of the lines found in the spectrum is shown in Col. 3 of Table 1. The uncertainty of the stronger lines is less than $10 \%$, while that of the weaker lines could be as large as $30 \%$. The SWS measurements were centered at RA(2000) $05^{\mathrm{h}} 27^{\mathrm{m}} 28.3^{\mathrm{s}}$ and $\operatorname{Dec}(2000)-12^{\circ} 41^{\prime} 48.4^{\prime \prime}$, which is very close to the center of the nebula. Because the diaphragm used was $14^{\prime \prime} \times 20^{\prime \prime}$ below $12 \mu \mathrm{m}$ and somewhat larger above this wavelength, the entire nebula fit within the diaphragm and was measured by the SWS. The LWS measurements (TDT 86801205) were made at essentially the same position and agree reasonably well with those reported and discussed by Liu et al. (2001) shown in the last column. Also shown in the last column are the measurements made by Willner et al. (1979) made with a $28^{\prime \prime}$ diaphragm below $\lambda=13 \mu \mathrm{m}$. The ISO measurements are to be preferred over those of Willner et al.

\subsection{ISO spectrum of IC 2165}

The ISO SWS observations were made only with the SWS02 observing template which has the advantage that
Table 1. ISO spectrum of IC 418. The measured lines are given in Col. 3. The last column gives the measurements of Willner et al. (1979, below $13 \mu \mathrm{m}$ ) and the measurements of Liu et al. (2001, above $50 \mu \mathrm{m})$ for comparison.

\begin{tabular}{|c|c|c|c|}
\hline Ident. & $\lambda(\mu \mathrm{m})$ & Intensity & Comparison \\
\hline Н г 6-4 & 2.626 & 24.7 & \\
\hline$?$ & 2.862 & 0.4 & \\
\hline Н I $11-5$ & 2.874 & 2.33 & \\
\hline Н г $10-5$ & 3.039 & 2.56 & \\
\hline Н г 9-5 & 3.297 & 4.58 & \\
\hline Н г 8-5 & 3.742 & 6.60 & 6.2 \\
\hline Н г $5-4$ & 4.053 & 44.8 & 28.0 \\
\hline [Ar II] & 6.985 & 31.4 & 49.0 \\
\hline Н г 6-5 & 7.462 & 14.3 & \\
\hline Н г 8-6 & 7.505 & 4.47 & \\
\hline [Ar III] & 8.994 & 38.4 & 20.0 \\
\hline$[\mathrm{S}$ Iv $]$ & 10.507 & 6.63 & \\
\hline$[\mathrm{Ne}$ II] & 12.816 & 278. & 280. \\
\hline [Ne III] & 15.558 & 49.8 & \\
\hline$[\mathrm{S}$ III] & 18.718 & 79.6 & \\
\hline [S III] & 33.487 & 13.7 & \\
\hline [Si II] & 34.821 & 4.90 & \\
\hline [O III] & 51.861 & 79.9 & 77.0 \\
\hline [N III] & 57.355 & 17.4 & 16.6 \\
\hline$\left[\mathrm{O}_{\mathrm{I}}\right]$ & 63.185 & 51.5 & 53.0 \\
\hline [O III] & 88.378 & 12.6 & 12.9 \\
\hline$[\mathrm{N}$ II $]$ & 121.99 & 1.48 & 0.84 \\
\hline$\left[\mathrm{O}_{\mathrm{I}}\right]$ & 145.572 & 1.43 & 1.17 \\
\hline$\left[\mathrm{C}_{\mathrm{II}}\right]$ & 157.789 & 5.76 & 5.20 \\
\hline
\end{tabular}

Intensity measured in units of $10^{-12} \mathrm{erg} \mathrm{cm}^{-2} \mathrm{~s}^{-1}$.

weaker intensities can be reliably measured, but has the disadvantage that some lines may be missed. The longwave observations were also made with an LWS02 template, but here all important lines were measured. The intensity of the lines found in the spectrum are shown in Table 2. The uncertainty of the stronger lines is less than $10 \%$, increasing for the weaker lines to $30 \%$. The two SWS02 measurements were slightly displaced from one another. TDT 70201606 was centered at $\mathrm{RA}(2000) 06^{\mathrm{h}} 21^{\mathrm{m}} 42.6^{\mathrm{s}}$ and $\operatorname{Dec}(2000)-12^{\circ} 59^{\prime} 10.3^{\prime \prime}$, while TDT 71002302 was centered at RA(2000) $06^{\mathrm{h}} 21^{\mathrm{m}} 42.8^{\mathrm{s}}$ and $\operatorname{Dec}(2000)-12^{\circ} 59^{\prime} 14.3^{\prime \prime}$. The latter measurement is closer to the center of the nebula as given in the NRAO/VLA sky survey (Condon et al. 1998). Because the diaphragm used was $14^{\prime \prime} \times 20^{\prime \prime}$ below $12 \mu \mathrm{m}$ and somewhat larger above this wavelength, it is possible that the entire nebula was only measured by the best centered measurement below $12 \mu \mathrm{m}$. Indeed, the fluxes measured in this spectral region are about $25 \%$ higher for the best centered mesurement. Above $12 \mu \mathrm{m}$ the two measurements differ by less than $10 \%$. The LWS measurements were made at essentially the same position but measurements were made of only three lines. Liu et al. (2001) did not report LWS measurements of this nebula. 
Table 2. ISO observations of IC 2165. The measured intensities are in units of $10^{-12} \mathrm{erg} \mathrm{cm}^{-2} \mathrm{~s}^{-1}$ ).

\begin{tabular}{|c|c|c|}
\hline Ident. & $\lambda(\mu \mathrm{m})$ & Intensity \\
\hline Не II 9-7 & 2.826 & 0.13 \\
\hline Н г $5-4$ & 4.053 & 2.81 \\
\hline [Mg IV] & 4.487 & 4.18 \\
\hline [Ar vI] & 4.530 & 1.82: \\
\hline$[\mathrm{Mg} \mathrm{v}]$ & 5.610 & 4.76 \\
\hline Н г 8-6 & 7.460 & 1.00: \\
\hline [Ne vi] & 7.655 & 0.52 : \\
\hline [Arv] & 7.903 & 0.75 \\
\hline [Ar III] & 8.993 & 2.27 \\
\hline$[\mathrm{S}$ IV $]$ & 10.510 & 27.4 \\
\hline$[\mathrm{Ne}$ II $]$ & 12.816 & 1.50 \\
\hline [Arv] & 13.103 & 1.25 \\
\hline$[\mathrm{Mg} \mathrm{v}]$ & 13.525 & 0.52 \\
\hline$[\mathrm{Ne} v]$ & 14.325 & 24.0 \\
\hline [Ne III] & 15.558 & 32.2 \\
\hline [S III] & 18.716 & 5.55 \\
\hline [Fe III] & 22.926 & \\
\hline$[\mathrm{Ne} v]$ & 24.320 & 21.3 \\
\hline [O IV] & 25.894 & 84.2 \\
\hline$[\mathrm{Fe}$ II $]$ & 25.988 & \\
\hline [S III] & 33.485 & 2.40 \\
\hline [Ne III] & 36.021 & 3.56 \\
\hline [O III] & 51.854 & 28.4 \\
\hline$[\mathrm{N}$ III $]$ & 57.385 & 4.53 \\
\hline [O III] & 88.393 & 8.06 \\
\hline
\end{tabular}

: Uncertain value.

\subsection{ISO spectrum of NGC 5882}

Only the SWS02 and LWS02 templates were used, so that it is possible that interesing lines were not observed. On the other hand these templates are much more sensitive so that more accurate intensities are obtained. In both cases (TDT 48400667 and TDT 48400668) the instrument was centered at $\operatorname{RA}(2000) 15^{\mathrm{h}} 16^{\mathrm{m}} 49.83^{\mathrm{s}}$ and $\operatorname{Dec}(2000)-45^{\circ} 38^{\prime} 56.1^{\prime \prime}$. This is within $1^{\prime \prime}$ of the center of the nebula (as given by Simbad), and since the HST image of the nebula has a diameter of $13.5^{\prime \prime}$, the entire nebula probably fits within the ISO diaphragm. This is confirmed below with a comparison with the $6 \mathrm{~cm}$ radio flux density. The line intensities of the nebula are given in Table 3 .

\section{Extinction}

There are several methods for obtaining the extinction: (1) comparison of radio emission with $\mathrm{H} \beta$ flux; (2) comparison of observed and theoretical Balmer decrement; (3) dip at $\lambda 2200 \AA$; (4) photometry of the exciting star. First, however, we will discuss the radio emission and the $\mathrm{H} \beta$ flux.
Table 3. ISO spectrum of NGC 5882. Colunm 3 gives our measured values. The last column gives the IRAS measurements (Pottasch et al. 1986) below $20 \mu \mathrm{m}$ and the values of Liu et al. (2001) above $50 \mu \mathrm{m}$. All intensities are in units of $10^{-12} \mathrm{erg} \mathrm{cm}^{-2} \mathrm{~s}^{-1}$ ).

\begin{tabular}{|c|c|c|c|}
\hline Ident. & $\lambda(\mu \mathrm{m})$ & Intensity & Comparison \\
\hline Н I 6-4 & 2.626 & 4.18 & \\
\hline Не п $10-8$ & 4.042 & 0.68 & \\
\hline Н г 5-4 & 4.052 & 7.78 & \\
\hline [Ar III] & 8.992 & 19.0 & \\
\hline$[\mathrm{S}$ IV $]$ & 10.511 & 212. & 230. \\
\hline$[\mathrm{Ne}$ II $]$ & 12.8 & & $\leq 20$. \\
\hline [Ne III] & 15.556 & 269. & $350 .:$ \\
\hline [S III] & 18.714 & 39.3 & 40. \\
\hline [Ar III] & 21.832 & 1.38 & \\
\hline [O IV] & 25.892 & 9.78 & \\
\hline [S III] & 33.482 & 17.3 & \\
\hline [Ne III] & 36.015 & 24.6 & \\
\hline [O III] & 51.829 & 184. & 171. \\
\hline$[\mathrm{N}$ III $]$ & 57.333 & 28.9 & 29. \\
\hline [O III] & 88.406 & 56.5 & 59. \\
\hline
\end{tabular}

\subsection{The $6 \mathrm{~cm}$ radio emission}

\subsubsection{IC 418}

The $6 \mathrm{~cm}$ flux density has been measured in the PMN survey (Griffith et al. 1994). They find 1716 mJy with a fixed width fit, and 1746 mJy with a general width fit. The nebula has also been measured by Milne \& Aller (1982) who find $1529 \mathrm{mJy}$ at $2 \mathrm{~cm}$, which, if optically thin, would imply $1733 \mathrm{mJy}$ at $6 \mathrm{~cm}$. We shall use $1733 \mathrm{mJy}$ in the present analysis.

\subsubsection{IC 2165}

This nebula has also been measured in the PMN survey by Griffith et al. (1994), who find 198 mJy with a fixed width fit, and $200 \mathrm{mJy}$ with a general width fit. The nebula has also been measured by Milne \& Aller (1982) who find $186 \mathrm{mJy}$ at $2 \mathrm{~cm}$ which, if optically thin, would imply $208 \mathrm{mJy}$ at $6 \mathrm{~cm}$. We shall use $200 \mathrm{mJy}$.

\subsubsection{NGC 5882}

The PMN survey (Wright et al. 1994) finds 397 mJy with a fixed width fit, and $373 \mathrm{mJy}$ with a general width fit. The same data has also been reduced by Gregory et al. (1994) who give $342 \mathrm{mJy}$. Because of the large difference between the various reductions, Condon has kindly rereduced this data. He finds (private communication) that the nebula appears to be slightly extended, with an integrated flux density of $389 \mathrm{mJy}$. We shall use this value. 


\subsection{The $H \beta$ flux}

The measured $\mathrm{H} \beta$ fluxes summarized by Cahn et al. (1992) will be used. For IC $418 \mathrm{H} \beta=2.70 \times 10^{-10} \mathrm{erg} \mathrm{cm}^{-2} \mathrm{~s}^{-1}$, for IC $2165 \mathrm{H} \beta=1.27 \times 10^{-11} \mathrm{erg} \mathrm{cm}^{-2} \mathrm{~s}^{-1}$ and for NGC $5882 \mathrm{H} \beta=4.20 \times 10^{-11} \mathrm{erg} \mathrm{cm}^{-2} \mathrm{~s}^{-1}$.

\subsection{The value of the extinction $E_{B-V}$}

Using the above values of the $6 \mathrm{~cm}$ radio flux densities and values of electron temperature and helium abundance which will presently be discussed, we obtain the intrinsic flux of $\mathrm{H} \beta$. For IC 418, IC 2165 and NGC 5882 the $\mathrm{H} \beta$ flux in units of $10^{-11} \mathrm{erg} \mathrm{cm}^{-2} \mathrm{~s}^{-1}$ is respectively 58.3, 4.98 and 12.7. Combining this with the measured value of $\mathrm{H} \beta$ gives a value of extinction $C=0.33$ or $E_{B-V}=0.23$ for IC $418, C=0.59$ or $E_{B-V}=0.40$ for IC 2165 , and $C=0.48$ or $E_{B-V}=0.33$ for NGC 5882. In these calculations, as well as in the rest of the paper, the extinction curve given by Fluks et al. (1994) has been used.

\subsubsection{The $\operatorname{Br} \alpha$ flux}

The $\operatorname{Br} \alpha$ flux (for which the extinction is small) can also be used to predict the intrinsic $\mathrm{H} \beta$ flux, using the theoretical spectrum (Hummer \& Storey 1987). After making the small extinction correction, and using the temperature and density given below, the $\mathrm{H} \beta$ value found for IC 418 is $5.89 \times 10^{-10} \mathrm{erg} \mathrm{cm}^{-2} \mathrm{~s}^{-1}$, which is essentially the same as found from the radio data. For IC 2165 it is $\mathrm{H} \beta=4.26 \times 10^{-11} \mathrm{erg} \mathrm{cm}^{-2} \mathrm{~s}^{-1}$ and for NGC 5882 it is $\mathrm{H} \beta=1.27 \times 10^{-10} \mathrm{erg} \mathrm{cm}^{-2} \mathrm{~s}^{-1}$. In both cases this is $20 \%$ lower than the $\mathrm{H} \beta$ found from the radio data. While this is a small amount, we regard it as significant. It is possible that the pointing could have been slightly off center in these two objects and a small part of the nebula was therefore not measured. But it could be that the radio flux density is too high for these two objects.

\subsubsection{Balmer decrement}

The extinction determined from the Balmer decrement differs somewhat according to the author. For IC 418 Henry et al. (2000) give $C=0.14$, Torres-Peimbert et al. (1980) find $C=$ 0.25 , Gutierrez-Moreno et al. (1988) give $C=0.37$ and Hyung et al. (1994) find $C=0.21$. For IC 2165 Gutierrez-Moreno et al. (1988) give $C=0.51$, Hyung (1994) finds $C=0.68$ and Kwitter et al. (2003) give $C=0.40$. For NGC 5882 GutierrezMoreno et al. (1988) give $C=0.33$, Kwitter et al. (2003) give $C=0.41$ and Guerrero \& Manchado (1999) find $C=0.48$.

These rather large differences could be real if the extinction were all local to the nebulae, varied within the nebulae and the individual authors measured at different positions in the nebulae. We regard errors of measurement as being the most likely origin of these differences. This is because there is no indication of extinction within the nebulae, and it is unlikely that interstellar extinction varies by such large amounts on spatial scales of a few arcsec. Besides this, the average values are very similar to the values found from the $6 \mathrm{~cm} / \mathrm{H} \beta$ method. This will have consequences in the next section where the visual spectrum is discussed.

\subsection{3. $\lambda 2200 \AA ̊$ extinction}

The extinction can be determined from the dip at $\lambda 2200 \AA$. For IC 418 Pottasch et al. (1977) give $E_{B-V}=0.19$ or $C=0.28$ using filter photometry on the ANS satellite. For IC 2165 Wolff et al. (2000) find $E_{B-V}=0.40$ or $C=0.59$ from HST measurements.

\subsubsection{Extinction from line ratios}

By comparing theoretical line ratios where the two lines are well separated in wavelength with the observed ratio, the extinction can be found. There are two line ratios which have been used with the line strengths and temperatures given below. First the ratio of the He II line $\lambda 1640 / \lambda 4686 \AA$ has been used in IC 2165, giving $C=0.60$. This same ratio was used in NGC 5882, giving $C=0.59$. This ratio could not be used in IC 418 because the nebular excitation is not high enough to observe these lines. Here the O II line ratio $\lambda 2470 / \lambda 7325 \AA$ can be used. These lines originate from the same levels and have a fixed theoretical ratio $(0.778)$ for the nebular conditions considered here. This leads to a value of extinction $C=0.36$ in IC 418. These values agree with those determined by other methods with the possible exception of NGC 5882. This somewhat high value may be caused by the IUE diaphragm being slightly smaller than the nebula.

\subsubsection{Extinction summary}

The extinction for the different wavelength regions has been corrected as follows:

1) The intrinsic value of $\mathrm{H} \beta$ used is that derived from the $6 \mathrm{~cm}$ radio flux density and is given in Sect. 3.3.

2) The infrared spectrum as observed is assumed to come from the entire nebula, and is corrected with the extinction given above. The value of extinction is quite small in this spectral region.

3) Different observers of the visual spectrum find different extinctions from the Balmer decrement. It is assumed that the extinction to a given nebula is, in reality independent of the observer and is due to incorrect compensation of wavelength sensitivity differences by the individual observer. We assume here that the error in sensitivity is compensated by the error in the derived extinction. This means that the corrected spectrum relative to $\mathrm{H} \beta$ given by each individual observer will be used. For a given nebula the individual observations will be averaged. This should be approximately correct, at least over the wavelength range for which the extinction is derived, which is usually the Balmer decrement, but may be the Paschen-Balmer ratio.

4) The (IUE) ultraviolet spectrum is related to the visible spectrum by assuming a theoretical He II $\lambda 1640 / \lambda 4686$ ratio (Hummer \& Storey 1987). This corrects both for the extinction and for the somewhat smaller diaphragm of the IUE. 
The further correction within the ultraviolet is made using the extinction given in Sect. 3.3 and the intrinsic extinction curve of Fluks et al. (1994). This method cannot be used for IC 418 since no nebular He II is measured. Here the same method is used with the $\mathrm{O}_{\text {II }}$ line ratio $\lambda 2471 / \lambda 7325$ $(=0.778)$.

\subsection{The visual spectrum}

\subsubsection{IC 418}

The visual spectrum has been measured by several people. The highest resolution spectrum is by Hyung et al. (1994), but reliable spectra have also been reported by Henry et al. (2000) and Torres-Peimbert et al. (1980), and the references cited therein, as well as by Gutierrez-Moreno et al. (1985). None of the measurements cover the entire nebula, but do cover a reasonably large area of the nebula, avoiding the central star. The measurements of Hyung et al. are preferred for the weak lines because of the much higher spectral resolution used. The results are shown in Table 4 where the Cols. 3-5 give the intensities measured by the various authors relative to $\mathrm{H} \beta=100$ for those lines which are of interest. As discussed above these lines have been corrected by the individual authors for extinction. In the last column the total intensities are given, normalized to the total flux: $\mathrm{H} \beta=5.83 \times 10^{-10} \mathrm{erg} \mathrm{cm}^{-2} \mathrm{~s}^{-1}$. An average value of the individual measurements, scaled to the total flux, is used, strongly weighted to the measurements of Hyung et al. (1994).

\subsubsection{IC 2165}

Similarly, the visible spectrum of IC 2165 has been measured by several authors. Their results are shown in Table 5, which are corrected for reddening by each author. The measurements refer to smaller regions of the nebula. It seems likely that the high resolution spectra made at Lick Observatory (Hyung 1994), are taken at the more central regions of the nebula and that the other measurements, which try to avoid the central star, represent the outer regions (the high resolution measurements can distinguish the nebula and stellar emission from the width of the lines). The last column of the table gives the total emission of the entire nebula, where the average gives more weight to the high resolution measurements, especially for the weaker lines. The [Ne v] $\lambda 3425 \AA$ line intensity was taken from Rowlands et al. (1993) who had a diaphragm large enough to measure the entire nebula.

\subsubsection{NGC 5882}

The visual spectrum of NGC 5882 has been measured by many authors. Three of the most extensive are shown in Table 6. The measurements of Tsamis et al. (2003) have the highest resolution and are given more weight in the average. Only the measurements of Tsamis et al. have a high enough resolution to resolve the [O II] doublet at $\lambda 3726 / \lambda 3729 \AA$; their ratio is used. It may be noted that these authors give relative line intensities averaged over the entire nebula, while the other measurements
Table 4. Visual Spectrum of IC 418 (total intensity in units of $10^{-11} \mathrm{erg} \mathrm{cm}^{-2} \mathrm{~s}^{-1}$ ).

\begin{tabular}{|c|c|c|c|c|c|}
\hline \multirow{2}{*}{$\begin{array}{c}\lambda \\
(\AA)\end{array}$} & \multirow[t]{2}{*}{ Ion } & \multicolumn{3}{|c|}{ Intensities } & \multirow{2}{*}{$\begin{array}{r}\text { Total } \\
\text { intens. }\end{array}$} \\
\hline & & (1) & (2) & (3) & \\
\hline 3726 & [O II] & 90.5 & & & 52.8 \\
\hline 3729 & [O II] & 37.7 & & & 22.0 \\
\hline 3869 & {$[\mathrm{Ne}$ III] } & 2.05 & 2.0 & 1.9 & 1.2 \\
\hline 4068 & [S II] & 2.44 & & & 1.43 \\
\hline 4076 & {$\left[\mathrm{~S}_{\mathrm{II}}\right]$} & 0.88 & & & 0.51 \\
\hline 4102 & $\mathrm{H} \delta$ & 25.2 & 19. & 24.0 & 14.7 \\
\hline 4267 & $\mathrm{C}_{\text {II }}$ & 0.38 & 0.3: & 0.46 & 0.22 \\
\hline 4340 & $\mathrm{H} \gamma$ & 47.0 & 41. & 46.5 & 27.1 \\
\hline 4363 & [O III] & 0.52 & $0.5:$ & 0.71 & 0.30 \\
\hline 4471 & $\mathrm{He}_{\mathrm{I}}$ & 3.59 & 3.0 & 3.2 & 2.1 \\
\hline 4861 & $\mathrm{H} \beta$ & 100 & 100 & 100 & 58.3 \\
\hline 5007 & [O III] & 85.9 & 123. & 130. & 61.2 \\
\hline 5518 & [Cl III] & 0.19 & 0.2 : & & 0.11 \\
\hline 5538 & [Cl III] & 0.38 & & & 0.22 \\
\hline 5755 & {$\left[\mathrm{~N}_{\mathrm{II}}\right]$} & 3.91 & 4.0 & 2.65 & 2.04 \\
\hline 5876 & $\mathrm{He}_{\mathrm{I}}$ & 10.9 & 10. & 11.0 & 6.36 \\
\hline 6312 & [S III] & 0.94 & 1.0: & & 0.548 \\
\hline 6563 & $\mathrm{H} \alpha$ & 350. & 286. & 282. & 169. \\
\hline 6578 & $\mathrm{C}_{\text {II }}$ & 0.48 & & & 0.28 \\
\hline 6584 & {$\left[\mathrm{~N}_{\mathrm{II}}\right]$} & 206.8 & 175. & 167. & 108. \\
\hline 6717 & [S II] & 3.59 & 3.0 & & 2.09 \\
\hline 6731 & {$\left[\mathrm{~S}_{\mathrm{II}}\right]$} & 6.79 & 6.0 & & 4.18 \\
\hline 7136 & [Ar III] & 6.18 & 8.0 & & 3.6 \\
\hline 7320 & [O II] & 15.7 & & & 9.15 \\
\hline 7330 & [O II] & 13.4 & & & 7.81 \\
\hline 8579 & [Cl II $]$ & 0.27 & & & 0.157 \\
\hline 9531 & {$\left[\mathrm{~S}_{\mathrm{III}}\right]$} & 38.1 & 81.: & & $26.3^{*}$ \\
\hline
\end{tabular}

(1) Hyung et al. (1994); (2) Henry et al. (2000); (3) Torres-Peimbert et al. (1980).

(:) Indicates uncertain values.

* The $\left[\mathrm{S}_{\text {III }}\right] 29531 \AA$ intensity was taken from Hippelein \& Munch (1981).

refer to smaller regions of the nebula. The last column of the table gives the total intensity of the nebula, which we shall use.

\subsection{The IUE ultraviolet spectrum}

\subsubsection{IC 418}

Many IUE observations of this nebula exist. We have used measurements centered at the position of the central star which probably includes the whole nebula. Several observations have been made of the nebula far enough from the central star so that no stellar light is measured. These spectra miss much of the nebular light and we have ignored them, as we have 
Table 5. Visual Spectrum of IC 2165 (total intensity in units of $10^{-12} \mathrm{erg} \mathrm{cm}^{-2} \mathrm{~s}^{-1}$ ).

\begin{tabular}{|c|c|c|c|c|c|}
\hline \multirow{2}{*}{$\begin{array}{c}\lambda \\
(\AA)\end{array}$} & \multirow[t]{2}{*}{ Ion } & \multicolumn{3}{|c|}{ Intensities } & \multirow{2}{*}{$\begin{array}{l}\text { Total } \\
\text { intens. }\end{array}$} \\
\hline & & (1) & (2) & (3) & \\
\hline 3425 & {$[\mathrm{Ne} v]$} & 58.9 & & 49.0 & $18.5^{*}$ \\
\hline 3726 & [O & 22.4 & & & 8.50 \\
\hline 3729 & [O II] & 13.8 & & & 4.50 \\
\hline 3869 & [Ne III] & 85.7 & 99.7 & 79.4 & 42.7 \\
\hline 4068 & {$[\mathrm{~S}$ II $]$} & 0.87 & & & 0.43 \\
\hline 4076 & {$[\mathrm{~S}$ II $]$} & 0.71 & & & 0.35 \\
\hline 4102 & $\mathrm{H} \delta$ & 25.8 & 23.8 & 30.2 & 12.9 \\
\hline 4163 & {$[\mathrm{Kv}]$} & 0.14 & & & 0.070 \\
\hline 4267 & $\mathrm{C}_{\text {II }}$ & 0.33 & 0.4 & 0.6: & 0.16 \\
\hline 4340 & $\mathrm{H} \gamma$ & 55.0 & 44.9 & 46.7 & 23.4 \\
\hline 4363 & [O III] & 20.8 & 16.6 & 21.4 & 10.4 \\
\hline 4471 & $\mathrm{He}_{\mathrm{I}}$ & 2.81 & 2.9 & 4.8 & 1.40 \\
\hline 4686 & He II & 63.5 & 39.8 & 41.7 & 22.6 \\
\hline 4861 & $\mathrm{H} \beta$ & 100 & 100 & 100 & 49.8 \\
\hline 5007 & [O III] & 1158. & 1085. & 1349. & 578. \\
\hline 5518 & [Cl III] & 0.33 & & 1.8 & 0.16 \\
\hline 5538 & {$\left[\mathrm{Cl}_{\mathrm{III}}\right]$} & 0.37 & & 2.3 & 0.18 \\
\hline 5755 & {$\left[\mathrm{~N}_{\mathrm{II}}\right]$} & 0.47 & 1.2 & 0.72 & 0.24 \\
\hline 5876 & $\mathrm{He}_{\mathrm{I}}$ & 7.64 & 8.7 & 12.3 & 3.98 \\
\hline 6101 & {$\left[\mathrm{~K}_{\mathrm{IV}}\right]$} & 0.32 & 0.3 & & 0.16 \\
\hline 6312 & [S III $]$ & 1.32 & 1.9 & 1.6: & 0.66 \\
\hline 6563 & $\mathrm{H} \alpha$ & 283. & 286. & 282. & 142. \\
\hline 6578 & $\mathrm{C}_{\text {II }}$ & 0.12 & & & 0.06 \\
\hline 6584 & {$\left[\mathrm{~N}_{\text {II }}\right]$} & 17.1 & 35.5 & 50.1 & 11.0 \\
\hline 6717 & {$\left[\mathrm{~S}_{\mathrm{II}}\right]$} & 0.86 & 1.7 & 2.4 & 0.6 \\
\hline 6731 & {$[\mathrm{~S}$ II] } & 1.34 & 2.8 & 4.4: & 1.01 \\
\hline 7005 & [Ar IV] & 2.08 & 1.3 & & 1.0 \\
\hline 7136 & [Ar III] & 7.12 & 10.1 & 9.55 & 4.0 \\
\hline 7170 & [Ar IV] & 0.31 & & & 0.15 \\
\hline 7236 & [Ar IV] & 0.26 & & & 0.13 \\
\hline 7320 & [O II] & 1.14 & & & 0.58 \\
\hline 7330 & [O II $]$ & 0.96 & & & 0.48 \\
\hline 8045 & {$\left[\mathrm{Cl}_{\mathrm{IV}}\right]$} & 0.73 & 0.9 & & 0.38 \\
\hline 9531 & {$\left[\mathrm{~S}_{\mathrm{III}}\right]$} & 20.8 & 46.8 & & 13 \\
\hline
\end{tabular}

(1) Hyung (1994); (2) Kwitter et al. (2003); (3) Gutierrez-Moreno et al. (1985).

The (:) indicates uncertain values.

* The [Ne v] $\lambda 3425 \AA$ intensity was taken from Rowlands et al. (1993).

ignored all the measurements made through the small aperture. Measurements have been made both with high resolution and with low resolution. These are shown separately in Table 7. For the high resolution we used the spectra SWP 04795, 19082, 12043, 40008, and LWR 03199 and 03200. Several spectra were required because when the faint lines could be well measured, the strong lines were saturated. For the low resolution we used SWP 14638 and the measurements already made earlier by one of us (Hyung et al. 1994).
Table 6. Visual Spectrum of NGC 5882 (total intensity in units of $10^{-12} \mathrm{erg} \mathrm{cm}^{-2} \mathrm{~s}^{-1}$ ).

\begin{tabular}{|c|c|c|c|c|c|}
\hline \multirow{2}{*}{$\begin{array}{c}\lambda \\
(\AA)\end{array}$} & \multirow[t]{2}{*}{ Ion } & \multicolumn{3}{|c|}{ Intensities } & \multirow{2}{*}{$\begin{array}{r}\text { Total } \\
\text { intens }\end{array}$} \\
\hline & & (1) & (2) & (3) & \\
\hline 3727 & {$\left[\mathrm{O}_{\mathrm{II}}\right]$} & 13.7 & 14.9 & 15.4 & 18.9 \\
\hline 3869 & {$[\mathrm{Ne} \mathrm{III}]$} & 75. & 89.6 & 93.1 & 116. \\
\hline 4102 & $\mathrm{H} \delta$ & 26.5 & 27.1 & 26.6 & 34.2 \\
\hline 4267 & $\mathrm{C}_{\text {II }}$ & 0.2 & 0.4 & 0.40 & 0.43 \\
\hline 4340 & $\mathrm{H} \gamma$ & 44.0 & 46.1 & 47.7 & 59.0 \\
\hline 4363 & [O III] & 5.5 & 5.4 & 5.56 & 6.98 \\
\hline 4471 & $\mathrm{He}_{\mathrm{I}}$ & 5.3 & 5.3 & 5.65 & 6.92 \\
\hline 4686 & He II & 2.9 & 3.7 & 2.75 & 3.9 \\
\hline 4711 & Ar IV & & & 2.60 & 3.3 \\
\hline 4740 & Ar IV & & & 2.99 & 3.8 \\
\hline 4861 & $\mathrm{H} \beta$ & 100 & 100 & 100 & 127. \\
\hline 5007 & [O III] & 1056. & 1045. & 1050. & 1335. \\
\hline 5518 & [Cl III] & 0.4 & 0.4 & 0.42 & 0.52 \\
\hline 5538 & {$\left[\mathrm{Cl}_{\text {III }}\right]$} & 0.5 & 0.5 & 0.51 & 0.65 \\
\hline 5755 & {$\left[\mathrm{~N}_{\text {II }}\right]$} & 0.2 & 0.2 & 0.27 & 0.30 \\
\hline 5876 & $\mathrm{He}_{\mathrm{I}}$ & 16.1 & 16.3 & 16.0 & 20.5 \\
\hline 6101 & {$\left[\mathrm{~K}_{\mathrm{IV}}\right]$} & & 0.2 & 0.12 & 0.16 \\
\hline 6312 & [S III] & 1.1 & 1.2 & 1.2 & 1.51 \\
\hline 6563 & $\mathrm{H} \alpha$ & 280 & 286. & 295. & 360. \\
\hline 6584 & {$\left[\mathrm{~N}_{\text {II }}\right]$} & 11.7 & 13.0 & 14.4 & 15.5 \\
\hline 6717 & {$\left[\mathrm{~S}_{\text {II }}\right]$} & 1.05 & 1.1 & 1.11 & 1.4 \\
\hline 6731 & {$\left[\mathrm{~S}_{\text {III }}\right]$} & 1.63 & 1.7 & 1.91 & 2.26 \\
\hline 7136 & [Ar III] & 15.5 & 15.8 & 14.2 & 18.8 \\
\hline 7236 & [Ar IV] & 0.1 & 0.2 & 0.083 & 0.13 \\
\hline 7325 & [O II] & 2.0 & 2.0 & 1.80 & 2.47 \\
\hline 8045 & [Cliv] & 0.6 & 0.7 & & 0.79 \\
\hline 9531 & [S III] & 65. & 54. & & 82. \\
\hline
\end{tabular}

(1) Guerrero \& Manchado (1999); (2) Kwitter et al. (2003); (3) Tsamis et al. (2003). These intensities are integrated over the entire nebula. (:) Indicates uncertain values.

The extinction correction, as already explained above, was made by assuming a theoretical ratio for the [O II] line ratio $\lambda 7325 / \lambda 2471 \AA$ which arise from the same level(s). This ratio has little temperature or density dependence. This give the corrected line intensity of $\lambda 2471 \AA$. The other lines were further corrected for extinction relative to $\lambda 2471 \AA$, using $E_{B-V}=0.24$. Correcting in this way automatically includes a diaphragm correction if part of the nebula was not included in the diaphragm. The results are shown in the last column of Table 7. 
Table 7. IUE Spectrum of IC 418. The intensity is in units of $10^{-12} \mathrm{erg} \mathrm{cm}^{-2} \mathrm{~s}^{-1}$.

\begin{tabular}{llccc}
\hline \hline \multirow{2}{*}{$\lambda$} & \multirow{2}{*}{ Ion $_{(\AA)}$} & \multicolumn{3}{c}{ Intensities } \\
\cline { 3 - 5 } & & $(1)$ & $(2)$ & $(3)$ \\
\hline 1335 & $\mathrm{C}_{\text {II }}$ & & 21.9 & 159. \\
1663 & $\mathrm{O}_{\text {III }}$ & $\leq 0.7$ & $\leq 0.6$ & $\leq 3.4$ \\
1750 & $\left.\mathrm{~N}_{\text {III }}\right]$ & 0.67 & 0.71 & 4.0 \\
1761 & $\mathrm{C}_{\text {II }}$ & 2.35 & 0.101 & 14.4 \\
1907.0 & $\left.\mathrm{C}_{\text {III }}\right]$ & 21.6 & & \\
1909.1 & $\left.\mathrm{C}_{\text {III }}\right]$ & 19.3 & & \\
1909 & $\left.\mathrm{C}_{\text {III }}\right]$ & & 32.0 & 189. \\
2325 & $\left.\mathrm{C}_{\text {II }}\right]$ & & 82.5 & 558. \\
2471.7 & {$\left[\mathrm{O}_{\text {II }}\right.$} & 18.3 & 23.6 & 132. \\
2800 & $\mathrm{Mg}_{\text {II }}$ & & 29.3 & 112. \\
\hline
\end{tabular}

(1) Measured intensity from high resolution spectra.

(2) Measured intensity from low resolution spectra.

(3) Intensity corrected for extinction.

\subsubsection{IC 2165}

Twenty IUE spectra have been taken, of which two are of high resolution. We have used two long exposure low resolution shortwave spectra, SWP 03639 and SWP 13585, supplemented by a short exposure spectrum, SWP 02461, for the strong lines which were somewhat saturated on the long exposure spectrum. For the longwavelength region LWR 05432 was used. We have also consulted the high resolution spectra to measure some weak lines and line ratios which were not resolvable on the low resolution spectra. From these spectra we found a $\mathrm{C}_{\text {III }} \lambda 1907 / \lambda 1909$ ratio of 1.27 and a $\mathrm{Ne}$ IV $\lambda 2422 / \lambda 2425$ ratio of 1.1. The low resolution intensities are shown in Table 8 . The central star of this nebula is weak and no traces of the central star are seen in these spectra.

\subsubsection{NGC 5882}

There are only two IUE spectra of this nebula, one in each spectral range. The central star is comparatively bright so that the continuum is dominated by the stellar spectrum. Three P Cygni profiles are clearly seen; they have the following terminal velocities and absorption eqivalent widths $(E W)$ :

$\mathrm{N} v \lambda 1240 \AA, v=-4580 \pm 300 \mathrm{~km} \mathrm{~s}^{-1}, E W=9.1 ; \mathrm{O} v \lambda 1371 \AA$, $v=-2310 \pm 200 \mathrm{~km} \mathrm{~s}^{-1}, E W=2.4 ; \mathrm{C}$ IV $\lambda 1549 \AA, v=-2740 \pm$ $150 \mathrm{~km} \mathrm{~s}^{-1}, E W=3.0$.

The terminal velocity for the $\mathrm{N} v$ line may be affected by a Lyman $\alpha$ absorption line.

The emission line strengths are shown in Table 9. For the three P Cygni profiles the intensity given refers to the stellar emission component.
Table 8. IUE Spectrum of IC 2165.

\begin{tabular}{|c|c|c|c|c|}
\hline \multirow{2}{*}{$\begin{array}{c}\lambda \\
(\AA)\end{array}$} & \multirow[t]{2}{*}{ Ion } & \multicolumn{2}{|c|}{ Intensities } & \multirow{2}{*}{$\begin{array}{c}\text { Ratio } \\
\text { (3) }\end{array}$} \\
\hline & & (1) & (2) & \\
\hline 1240 & $\mathrm{Nv}$ & 6.6 & 23.3 & 0.47 \\
\hline 1401 & O IV] & 11.8 & 25.6 & 0.514 \\
\hline 1485 & $\mathrm{~N}$ iv] & 9.0 & 16.7 & 0.335 \\
\hline 1550 & Civ & 243. & 478. & 9.56 \\
\hline 1640 & $\mathrm{He}_{\text {II }}$ & 96. & 178. & 3.57 \\
\hline 1663 & O III] & 10.4 & 18.9 & 0.38 \\
\hline 1750 & $\mathrm{~N}$ III] & 12.1 & 20.7 & 0.414 \\
\hline 1762 & $\mathrm{C}_{\text {II }}$ & 2.5: & 4.3 & 0.087 \\
\hline 1883 & $\mathrm{Si}$ III] & 2.0 & 3.7 & 0.074 \\
\hline 1909 & C III] & 193. & 376. & 7.55 \\
\hline 2325 & $\left.\mathrm{C}_{\mathrm{II}}\right]$ & 10.7 & 24.9 & 0.501 \\
\hline 2424 & {$[\mathrm{Ne} \mathrm{IV}]$} & 18.5 & 31.5 & 0.633 \\
\hline 2734 & $\mathrm{He}_{\text {II }}$ & 5.8 & 5.7 & 0.114 \\
\hline 2785 & {$[\mathrm{Mg} \mathrm{v}]$} & 3.1 & 2.82 & 0.057 \\
\hline 2798 & $\mathrm{Mg}_{\text {II }}$ & 0.15 & 0.14 & 0.0028 \\
\hline 2836 & $\mathrm{O}_{\text {III }}$ & 4.9 & 4.24 & 0.085 \\
\hline 3024 & $\mathrm{O}_{\text {III }}$ & 3.1 & 2.33 & 0.047 \\
\hline 3047 & O III & 7.7 & 5.82 & 0.117 \\
\hline 3133 & $\mathrm{O}_{\text {III }}$ & 50.7 & 94.5 & 1.90 \\
\hline 3203 & He II & 14.3 & 9.54 & 0.192 \\
\hline
\end{tabular}

(1) I(lines) in intensity units $10^{-13} \mathrm{erg} \mathrm{cm}^{-2} \mathrm{~s}^{-1}$.

(2) $I$ (lines) extinction corrected in intensity units $10^{-12} \mathrm{erg} \mathrm{cm}^{-2} \mathrm{~s}^{-1}$.

(3) $I($ line $) / I(\mathrm{H} \beta)$ after correction for extinction.

\section{Chemical composition of the nebulae}

The method of analysis is the same as used in the papers cited in the introduction. First the electron density and temperature as function of the ionization potential are determined. Then the ionic abundances are determined, using density and temperature appropriate for the ion under consideration. Then the element abundances are found for those elements in which a sufficient number of ionic abundances have been derived.

\subsection{Electron density}

The ions used to determine $N_{\mathrm{e}}$ are listed in the first column of Table 10 (for IC 418), Table 11 (for IC 2165), and Table 12 (for NGC 5882). The ionization potential required to reach that ionization stage, and the wavelengths of the lines used, are given in Cols. 2 and 3 of the tables. Note that the wavelength units are $\AA$ when 4 ciphers are given and microns when 3 ciphers are shown. The observed ratio of the lines is given in the fourth column; the corresponding $N_{\mathrm{e}}$ is given in the fifth column. The temperature used is discussed in the following section, but is 
Table 9. IUE Spectrum of NGC 5882.

\begin{tabular}{|c|c|c|c|c|}
\hline \multirow{2}{*}{$\begin{array}{c}\lambda \\
(\AA)\end{array}$} & \multirow[t]{2}{*}{ Ion } & \multicolumn{2}{|c|}{ Intensities } & \multirow{2}{*}{$\begin{array}{c}\text { Ratio } \\
\text { (3) }\end{array}$} \\
\hline & & (1) & (2) & \\
\hline 1240 & $\mathrm{Nv}$ & 13.8 & 50.6 & \\
\hline 1270 & $?$ & 2.7 & 9.5 & 0.070 \\
\hline 1280 & $?$ & 1.2 & 4.2 & 0.031 \\
\hline 1376 & $\mathrm{Ov}$ & 7.4 & 18.0 & \\
\hline 1401 & O Iv] & $\leq 2.3$ & $\leq 5.5$ & $\leq 0.041$ \\
\hline 1550 & $\mathrm{C}_{\mathrm{IV}}$ & 8.7 & 19.5 & \\
\hline 1575 & $?$ & 2.8 & 6.1 & 0.044 \\
\hline 1640 & $\mathrm{He}_{\text {II }}$ & 12.6 & 27.5 & 0.201 \\
\hline 1663 & $\left.\mathrm{O}_{\mathrm{III}}\right]$ & 4.1 & 8.95 & 0.066 \\
\hline 1750 & $\left.\mathrm{~N}_{\text {III }}\right]$ & 2.7 & 5.56 & 0.041 \\
\hline 1814 & $?$ & 1.1: & 2.3 & 0.017 \\
\hline 1884 & Si III] & 1.5 & 3.1 & 0.022 \\
\hline 1909 & $\mathrm{C}_{\text {III] }}$ & 224 & 48.9 & 0.358 \\
\hline 2831 & $\mathrm{O}_{\mathrm{III}}$ & 5.3 & 6.3 & 0.046 \\
\hline 3049 & $\mathrm{O}_{\text {III }}$ & 4.4 & 4.0 & 0.030 \\
\hline 3133 & $\mathrm{O}_{\text {III }}$ & 18.8 & 18.0 & 0.132 \\
\hline 3187 & $\mathrm{Fe}_{\mathrm{II}}$ ? & 4.8 & 4.5 & 0.032 \\
\hline 3203 & $\mathrm{He}_{\text {II }}$ & 1.8 & 1.69 & 0.012 \\
\hline
\end{tabular}

(1) $I$ (lines) in intensity units $10^{-13} \mathrm{erg} \mathrm{cm}^{-2} \mathrm{~s}^{-1}$.

(2) $I$ (lines) extinction corrected in intensity units $10^{-12} \mathrm{erg} \mathrm{cm}^{-2} \mathrm{~s}^{-1}$.

(3) $I($ line $) / I(\mathrm{H} \beta)$ after correction for extinction and possible diaphragm size effects.

unimportant since these line ratios are essentially determined by the density.

There is no indication that the electron density varies with ionization potential in a systematic way in either of the nebulae. As already pointed out by Liu et al. (2001) the [O III] lines always give a lower density than the other lines. Ignoring these lines, the electron density appears to be about $12000 \mathrm{~cm}^{-3}$ for IC 418 , about $5000 \mathrm{~cm}^{-3}$ for IC 2165 and $4000 \mathrm{~cm}^{-3}$ NGC 5882 . The error is about $20 \%$. It is interesting to compare this value of the density with the rms density found from the $\mathrm{H} \beta$ line. This depends on the distance of the nebula which isn't accurately known, and on the angular size of the nebula. For this calculation we shall use a distance of $1 \mathrm{kpc}$ for IC 418 and for NGC 5882 and a distance of $3 \mathrm{kpc}$ for IC 2165. A sphere of radius of $6.5^{\prime \prime}$ will represent IC 418 , a radius of 4 " will represent IC 2165, and 7" will represent NGC 5882. These are very uncertain values. The $\mathrm{H} \beta$ flux has been given above and the electron temperature will be discussed below. We obtain the uncertain rms values of $12000 \mathrm{~cm}^{-3}$ for IC 418 , and $5100 \mathrm{~cm}^{-3}$ for both NGC 5882 and IC 2165 . In spite of the uncertainties involved in these calculations (the uncertain distance and the assumption of a spherical homogeneous nebula), there is a strong similarity of these values to the forbidden line densities. This probably indicates that inhomogeneities do not play a dominant role in determining the density. We will
Table 10. Electron density indicators in IC 418.

\begin{tabular}{lcccc}
\hline \hline Ion & $\begin{array}{c}\text { Ioniz. } \\
\text { pot. }(\mathrm{eV})\end{array}$ & $\begin{array}{c}\text { Lines } \\
\text { used }\end{array}$ & $\begin{array}{c}\text { Observed } \\
\text { ratio }\end{array}$ & $\begin{array}{c}N_{\mathrm{e}} \\
\left(\mathrm{cm}^{-3}\right)\end{array}$ \\
\hline$\left[\mathrm{S}_{\text {III }}\right.$ & 10.4 & $6731 / 6716$ & 2.0 & 10000 \\
{$\left[\mathrm{O}_{\text {II }}\right]$} & 13.6 & $3626 / 3729$ & 2.4 & 12000 \\
{$\left[\mathrm{~S}_{\text {III }}\right]$} & 23.3 & $33.5 / 18.7$ & 0.172 & 10000 \\
{$\left[\mathrm{Cl}_{\text {III }}\right]$} & 23.8 & $5538 / 5518$ & 2.0 & 14000 \\
{$\left[\mathrm{C}_{\text {III }}\right]$} & 24.4 & $1907 / 1909$ & 1.12 & 10000 \\
{$[\mathrm{O}$ III $]$} & 35.1 & $51.9 / 88.4$ & 6.34 & 6500 \\
\hline
\end{tabular}

Table 11. Electron density indicators in IC 2165.

\begin{tabular}{lcccc}
\hline \hline Ion & $\begin{array}{c}\text { Ioniz. } \\
\text { pot. }(\mathrm{eV})\end{array}$ & $\begin{array}{c}\text { Lines } \\
\text { used }\end{array}$ & $\begin{array}{c}\text { Observed } \\
\text { ratio }\end{array}$ & $\begin{array}{c}N_{\mathrm{e}} \\
\left(\mathrm{cm}^{-3}\right)\end{array}$ \\
\hline$\left[\mathrm{S}_{\text {II }}\right]$ & 10.4 & $6731 / 6716$ & 1.68 & 4600 \\
{$\left[\mathrm{O}_{\text {II }}\right]$} & 13.6 & $3626 / 3729$ & 1.89 & 5800 \\
{$\left[\mathrm{~S}_{\text {III }}\right]$} & 23.3 & $33.5 / 18.7$ & 0.432 & 2900 \\
{$\left[\mathrm{Cl}_{\text {III }}\right]$} & 23.8 & $5538 / 5518$ & 1.13 & 4800 \\
{$\left[\mathrm{C}_{\text {III }}\right]$} & 24.4 & $1907 / 1909$ & 1.27 & 5000 \\
{$\left[\mathrm{O}_{\text {III }}\right]$} & 35.1 & $51.9 / 88.4$ & 3.52 & 2000 \\
{$[\mathrm{Ar}$ IV $]$} & 40.7 & $4711 / 4740$ & 1.10 & 4500 \\
{$[\mathrm{Ne}$ IV $]$} & 63.5 & $2425 / 2422$ & 0.91 & 8000 \\
\hline
\end{tabular}

Table 12. Electron density indicators in NGC 5882.

\begin{tabular}{lcccc}
\hline \hline Ion & $\begin{array}{c}\text { Ioniz. } \\
\text { pot. }(\mathrm{eV})\end{array}$ & $\begin{array}{c}\text { Lines } \\
\text { used }\end{array}$ & $\begin{array}{c}\text { Observed } \\
\text { ratio }\end{array}$ & $\begin{array}{c}N_{\mathrm{e}} \\
\left(\mathrm{cm}^{-3}\right)\end{array}$ \\
\hline$\left[\mathrm{S}_{\text {III }}\right]$ & 10.4 & $6731 / 6716$ & 1.61 & 3100 \\
{$[\mathrm{O}$ II $]$} & 13.6 & $3626 / 3729$ & 2.05 & 5000 \\
{$\left[\mathrm{~S}_{\text {III }}\right]$} & 23.3 & $33.5 / 18.7$ & 0.44 & 2700 \\
{$\left[\mathrm{Cl}_{\text {III }}\right]$} & 23.8 & $5538 / 5518$ & 1.25 & 4300 \\
{$\left[\mathrm{O}_{\text {III }}\right]$} & 35.1 & $51.9 / 88.4$ & 3.26 & 1400 \\
{$[\mathrm{Ar}$ IV $]$} & 40.7 & $4740 / 4711$ & 1.15 & 4500 \\
\hline
\end{tabular}

use the forbidden line densities in further discussion of the abundances.

\subsection{Electron temperature}

A number of ions have lines originating from energy levels far enough apart that their ratio is sensitive to the electron temperature. These are listed in Tables 13-15, which are arranged similarly to the previous tables. The electron temperature for IC 418 and NGC 5882 remains roughly constant as a function of ionization potential at a similar rather low value. This is not the case for IC 2165, where the temperature clearly increases as a function of increasing ionization potential. 
Table 13. Electron temperature indicators in IC 418.

\begin{tabular}{|c|c|c|c|c|}
\hline Ion & $\begin{array}{c}\text { Ioniz. } \\
\text { pot. }(\mathrm{eV})\end{array}$ & $\begin{array}{c}\text { Lines } \\
\text { used }\end{array}$ & $\begin{array}{l}\text { Observed } \\
\text { ratio }\end{array}$ & $\begin{array}{c}T_{\mathrm{e}} \\
(\mathrm{K})\end{array}$ \\
\hline$\left[\mathrm{N}_{\text {II }}\right]$ & 14.5 & $5755 / 6584$ & 0.0189 & 9400 \\
\hline [S III] & 23.3 & $6312 / 18.7$ & 0.0678 & 9500 \\
\hline [S III $]$ & 23.3 & $6312 / 9531$ & 0.0208 & 9200 \\
\hline [Ar III] & 27.6 & $7136 / 8.99$ & 0.938 & 9100 \\
\hline$[\mathrm{N}$ III] & 29.6 & $57.4 / 1750$ & 4.35 & 8500 \\
\hline [O III] & 35.1 & $4363 / 5007$ & 0.00490 & 9100 \\
\hline [O III] & 35.1 & $1663 / 5007$ & 0.0056 & 9400 \\
\hline$[\mathrm{Ne}$ III] & 41.0 & $3869 / 15.5$ & 0.241 & 8000 \\
\hline
\end{tabular}

Table 14. Electron temperature indicators in IC 2165.

\begin{tabular}{lcccc}
\hline \hline Ion & $\begin{array}{c}\text { Ioniz. } \\
\text { pot. (eV) }\end{array}$ & $\begin{array}{c}\text { Lines } \\
\text { used }\end{array}$ & $\begin{array}{c}\text { Observed } \\
\text { ratio }\end{array}$ & $\begin{array}{c}T_{\mathrm{e}} \\
(\mathrm{K})\end{array}$ \\
\hline$\left[\mathrm{N}_{\text {III }}\right]$ & 14.5 & $5755 / 6584$ & 0.0218 & 10300 \\
{$\left[\mathrm{~S}_{\mathrm{III}}\right]$} & 23.3 & $6312 / 18.7$ & 0.119 & 13400 \\
{$\left[\mathrm{~S}_{\mathrm{III}}\right]$} & 23.3 & $6312 / 9531$ & 0.0508 & 13500 \\
{$[\mathrm{Ar}$ III $]$} & 27.6 & $7136 / 8.99$ & 1.76 & 14000 \\
{$\left[\mathrm{~N}_{\text {III }}\right]$} & 29.6 & $57.4 / 1750$ & 0.219 & 15500 \\
{$[\mathrm{O}$ III $]$} & 35.1 & $4363 / 5007$ & 0.0180 & 14500 \\
{$[\mathrm{O}$ III $]$} & 35.1 & $1663 / 5007$ & 0.0327 & 14400 \\
{$[\mathrm{Ne}$ III $]$} & 41.0 & $3868 / 15.5$ & 1.33 & 12500 \\
{$[\mathrm{O}$ IV $]$} & 54.7 & $1400 / 25.9$ & 0.304 & 19000 \\
{$[\mathrm{Ne}$ v $]$} & 97.1 & $3425 / 24.3$ & 0.869 & 20000 \\
{$[\mathrm{Mg}$ v $]$} & 109.3 & $2785 / 5.61$ & 0.592 & 17000 \\
\hline
\end{tabular}

Table 15. Electron temperature indicators in NGC 5882.

\begin{tabular}{|c|c|c|c|c|}
\hline Ion & $\begin{array}{c}\text { Ioniz. } \\
\text { pot. }(\mathrm{eV})\end{array}$ & $\begin{array}{l}\text { Lines } \\
\text { used }\end{array}$ & $\begin{array}{c}\text { Observed } \\
\text { ratio }\end{array}$ & $\begin{array}{l}T_{\mathrm{e}} \\
(\mathrm{K})\end{array}$ \\
\hline$\left[\mathrm{N}_{\mathrm{II}}\right]$ & 14.5 & $5755 / 6584$ & 0.0175 & 9800 \\
\hline [S III] & 23.3 & $6312 / 18.7$ & 0.0387 & 9500 \\
\hline [S III] & 23.3 & $6312 / 9531$ & 0.0185 & 8900 \\
\hline [Ar III] & 27.6 & $7136 / 8.99$ & 0.99 & 9700 \\
\hline [N III] & 29.6 & $57.4 / 1750$ & 5.20 & 9400 \\
\hline [O III] & 35.1 & $4363 / 5007$ & 0.00523 & 9400 \\
\hline [O III] & 35.1 & $1663 / 5007$ & 0.00667 & 9800 \\
\hline [Ne III] & 41.0 & $3868 / 15.5$ & 0.431 & 8900 \\
\hline
\end{tabular}

\subsection{Ionic and element abundances}

The ionic abundances have been determined using the following equation:

$\frac{N_{\text {ion }}}{N_{\mathrm{p}}}=\frac{I_{\text {ion }}}{I_{\mathrm{H} \beta}} N_{\mathrm{e}} \frac{\lambda_{\mathrm{ul}}}{\lambda_{\mathrm{H} \beta}} \frac{\alpha_{\mathrm{H} \beta}}{A_{\mathrm{ul}}}\left(\frac{N_{\mathrm{u}}}{N_{\text {ion }}}\right)^{-1}$

where $I_{\mathrm{ion}} / I_{\mathrm{H} \beta}$ is the measured intensity of the ionic line compared to $\mathrm{H} \beta, N_{\mathrm{p}}$ is the density of ionized hydrogen, $\lambda_{\mathrm{ul}}$ is the
Table 16. Ionic concentrations and chemical abundances in IC 418 . Wavelength in Angstrom for all values of $\lambda$ above 1000, otherwise in $\mu \mathrm{m}$.

\begin{tabular}{lccccc}
\hline \hline Ion & $\lambda$ & Intens./H $\beta$ & $N_{\text {ion }} / N_{\mathrm{p}}$ & ICF & $N_{\text {el. }} / N_{\mathrm{p}}$ \\
\hline $\mathrm{He}^{+}$ & 5875 & 10.9 & 0.072 & & \\
$\mathrm{C}^{+}$ & 2325 & 96.0 & $4.03(-4)$ & & \\
$\mathrm{C}^{++}$ & 1909 & 32.4 & $2.15(-4)$ & 1 & $6.2(-4)$ \\
$\mathrm{N}^{+}$ & 6584 & 185. & $5.72(-5)$ & & \\
$\mathrm{N}^{+}$ & 122 & 0.254 & $6.00(-5)$ & & \\
$\mathrm{N}^{++}$ & 1750 & 0.685 & $2.50(-5)$ & & \\
$\mathrm{N}^{++}$ & 57 & 2.99 & $4.16(-5)$ & 1 & $9.5(-5)$ \\
$\mathrm{O}^{+}$ & 3727 & 138. & $2.40(-4)$ & & \\
$\mathrm{O}^{+}$ & 7325 & 29. & $3.25(-4)$ & & \\
$\mathrm{O}^{++}$ & 5007 & 105. & $5.85(-5)$ & & \\
$\mathrm{O}^{++}$ & 52 & 13.7 & $11.0(-5)$ & 1 & $3.5(-4)$ \\
$\mathrm{Ne}^{+}$ & 12.8 & 47.9 & $8.10(-5)$ & & \\
$\mathrm{Ne}^{++}$ & 15.5 & 8.55 & $6.80(-6)$ & 1 & $8.8(-5)$ \\
$\mathrm{S}^{+}$ & 6731 & 6.80 & $8.95(-7)$ & & \\
$\mathrm{S}^{++}$ & 18.7 & 13.7 & $3.10(-6)$ & & \\
$\mathrm{S}^{++}$ & 6312 & 0.94 & $3.30(-6)$ & & \\
$\mathrm{S}^{++}$ & 9532 & 45.1 & $3.43(-6)$ & & \\
$\mathrm{S}^{+3}$ & 10.5 & 1.14 & $5.20(-8)$ & 1 & $4.4(-6)$ \\
$\mathrm{Ar}^{+}$ & 6.99 & 5.39 & $7.20(-7)$ & & \\
$\mathrm{Ar}^{++}$ & 8.99 & 6.60 & $7.74(-7)$ & & \\
$\mathrm{Ar}^{++}$ & 7136 & 6.2 & $7.67(-7)$ & 1.2 & $1.8(-6)$ \\
$\mathrm{Cl}^{+}$ & 8579 & 0.27 & $3.45(-8)$ & & \\
$\mathrm{Cl}^{++}$ & 5538 & 0.376 & $7.15(-8)$ & 1.1 & $1.2(-7)$ \\
$\mathrm{C}^{++}$ & 4267 & 0.376 & $4.13(-4)$ & & \\
$\mathrm{C}^{++}$ & 6578 & 0.48 & $4.44(-4)$ & & \\
$\mathrm{C}^{++}$ & 1761 & 2.48 & $7.04(-4)$ & & \\
\hline & & & & & \\
\hline
\end{tabular}

Intensities given with respect to $\mathrm{H} \beta=100$.

wavelength of this line, $\lambda_{\mathrm{H} \beta}$ is the wavelength of $\mathrm{H} \beta, \alpha_{\mathrm{H} \beta}$ is the effective recombination coefficient for $\mathrm{H} \beta, A_{\mathrm{ul}}$ is the Einstein spontaneous transition rate for the line, and $N_{\mathrm{u}} / N_{\text {ion }}$ is the ratio of the population of the level from which the line originates to the total population of the ion. This ratio has been determined using a five level atom.

\subsubsection{IC 418}

The results are given in Table 16, where the first column lists the ion concerned, and the second column the line used for the abundance determination. The third column gives the intensity of the line used relative to $\mathrm{H} \beta=100$. The fourth column gives the ionic abundances, and the fifth column gives the Ionization Correction Factor (ICF). This has been determined empirically. Notice that the ICF is unity (or almost unity) and the element abundances, given in the last column, are probably well determined. The carbon recombination line abundances are given at the end of the table.

The abundances in IC 418 are in general very similar to solar abundances. This will be discussed in detail presently. The 
abundances of oxygen, nitrogen, neon and argon are close to those of the sun. Sulfur is lower than solar, but this is true in most nebulae and it is likely that the solar abundance is anomalous. Carbon is the only element with a substantially higher abundance: a factor of three above solar. The helium abundance cannot be determined because there may be an important amount of neutral helium present.

\subsubsection{IC 2165}

The results are given in Table 17 which has the same format as the previous table.

The abundances in IC 2165 resemble those of IC 418 quite closely, although the abundances of almost all elements are about $20 \%$ lower. The carbon/oxygen ratio is about two in both cases, and the nitrogen/oxygen is very similar to the solar value.

\subsubsection{NGC 5882}

The results are given in Table 18 which has the same format as the previous two tables. The abundances in this nebula are very close to the solar abundances (see Table 21). In particular, carbon and oxygen are essentially solar. Carbon has not been produced in the course of the evolution of the central star, as it has been in IC 418 and IC 2165. Only nitrogen is somewhat higher than solar.

\section{Comparison with other abundance determinations}

Tables 19-21 show a comparison of our abundances with the most important determinations in the past 20 years. There is marginal agreement, usually to within a factor of two or three. It is rather surprising that such differences exist, even for oxygen. A comparison is also made with the solar abundance (Anders \& Grevesse 1989; Grevesse \& Sauval 1998; and Allende Prieto et al. 2001, 2002). Note that for sulfur and chlorine more weight has been given to the abundance determination in meteorites since this determination is more accurate than for the sun itself.

The helium abundance has been derived using the theoretical work of Benjamin et al. (1999). For recombination of singly ionized helium, most weight is given to the $\lambda 5875 \AA$ line, because the theoretical determination of this line is the most reliable. The abundance of helium in IC 418 is a lower limit since the ionization in this nebula is so low that much neutral helium may exist. Two abundances are given for Hyung et al. 1994 in the case of IC 418 and for Hyung 1994 in the case of IC 2165. The first refers to the method used here and is referred to as ICF (ionization correction factor), and the second determination is with the use of a nebular model.

\subsection{Errors}

It is difficult to determine the errors in the abundance determination for the following reason. The error can occur at several stages in the determination. An error can occur in the intensity
Table 17. Ionic concentrations and chemical abundances in IC 2165. Wavelength in Angstrom for all values of $\lambda$ above 1000, otherwise in $\mu \mathrm{m}$.

\begin{tabular}{|c|c|c|c|c|c|}
\hline Ion & $\lambda$ & Intens./H $\beta$ & $N_{\text {ion }} / N_{\mathrm{p}}$ & ICF & $N_{\mathrm{el} .} / N_{\mathrm{p}}$ \\
\hline $\mathrm{He}^{+}$ & 5875 & 8.0 & 0.048 & & \\
\hline $\mathrm{He}^{+}$ & 4471 & 2.81 & 0.050 & & \\
\hline $\mathrm{He}^{++}$ & 4686 & 45.5 & 0.041 & 1 & 0.091 \\
\hline $\mathrm{C}^{+}$ & 2325 & 50.1 & $4.56(-5)$ & & \\
\hline $\mathrm{C}^{++}$ & 1909 & 755. & $3.14(-4)$ & & \\
\hline $\mathrm{C}^{+3}$ & 1549 & 956. & $1.18(-4)$ & 1 & $4.8(-4)$ \\
\hline $\mathrm{N}^{+}$ & 6584 & 22.1 & $3.06(-6)$ & & \\
\hline $\mathrm{N}^{++}$ & 1750 & 41.4 & $4.79(-5)$ & & \\
\hline $\mathrm{N}^{++}$ & 57 & 9.1 & $4.9(-5)$ & & \\
\hline $\mathrm{N}^{+3}$ & 1485 & 33.5 & $1.29(-5)$ & & \\
\hline $\mathrm{N}^{+4}$ & 1240 & 47.0 & $8.1(-6)$ & 1 & $7.3(-5)$ \\
\hline $\mathrm{O}^{+}$ & 3727 & 26.1 & $8.2(-6)$ & & \\
\hline $\mathrm{O}^{++}$ & 5007 & 1160. & $1.64(-4)$ & & \\
\hline $\mathrm{O}^{++}$ & 51.9 & 57.1 & $2.0(-4)$ & & \\
\hline $\mathrm{O}^{+3}$ & 25.8 & 170. & $6.5(-5)$ & 1 & $2.7(-4)$ \\
\hline $\mathrm{Ne}^{+}$ & 12.8 & 3.0 & $3.56(-6)$ & & \\
\hline $\mathrm{Ne}^{++}$ & 15.5 & 64.6 & $3.98(-5)$ & & \\
\hline $\mathrm{Ne}^{+3}$ & 2425 & 63.3 & $8.0(-6)$ & & \\
\hline $\mathrm{Ne}^{+4}$ & 24.3 & 43.0 & $6.5(-6)$ & & \\
\hline $\mathrm{Ne}^{+5}$ & 7.65 & 1.05 & $3.7(-8)$ & 1 & $5.8(-5)$ \\
\hline $\mathrm{S}^{+}$ & 6731 & 1.87 & $9.0(-8)$ & & \\
\hline $\mathrm{S}^{++}$ & 18.7 & 11.2 & $1.2(-6)$ & & \\
\hline $\mathrm{S}^{++}$ & 6312 & 1.32 & $1.08(-6)$ & & \\
\hline $\mathrm{S}^{+3}$ & 10.5 & 62.1 & $1.7(-6)$ & 1.5 & $4.5(-6)$ \\
\hline $\mathrm{Ar}^{++}$ & 8.99 & 4.56 & $4.05(-7)$ & & \\
\hline $\mathrm{Ar}^{++}$ & 7136 & 8.03 & $3.87(-7)$ & & \\
\hline $\mathrm{Ar}^{+3}$ & 4740 & 5.8 & $5.6(-7)$ & & \\
\hline $\mathrm{Ar}^{+4}$ & 7.90 & 1.51 & $6.14(-8)$ & & \\
\hline $\mathrm{Ar}^{+5}$ & 4.54 & 3.66 & $5.80(-8)$ & 1.1 & $1.2(-6)$ \\
\hline $\mathrm{Cl}^{+}$ & 8577 & 0.020 & $1.4(-9)$ & & \\
\hline $\mathrm{Cl}^{++}$ & 5538 & 0.36 & $2.4(-8)$ & & \\
\hline $\mathrm{Cl}^{+3}$ & 8046 & 0.76 & $3.5(-8)$ & 1.7 & $1.1(-7)$ \\
\hline $\mathrm{K}^{+3}$ & 6101 & 0.32 & $1.06(-8)$ & & \\
\hline $\mathrm{K}^{+4}$ & 4164 & 0.14 & $2.0(-8)$ & 2 & $6.2(-8)$ \\
\hline $\mathrm{Ca}^{+4}$ & 5310 & 0.12 & $7.6(-9)$ & & \\
\hline $\mathrm{Si}^{++}$ & 1892 & 7.4 & $9.6(-7)$ & 3: & $3.0(-6)$ : \\
\hline $\mathrm{C}^{++}$ & 4267 & .36 & $3.64(-4)$ & & \\
\hline $\mathrm{C}^{++}$ & 6578 & 0.12 & $1.41(-4)$ & & \\
\hline $\mathrm{C}^{++}$ & 1761 & 8.7 & $2.33(-3)$ & & \\
\hline
\end{tabular}

Intensities given with respect to $\mathrm{H} \beta=100$.

determination and this can be specified: it is probably less than $30 \%$ and almost certainly is lower for the stronger lines. A related error may occur because the infrared and ultraviolet measurements are an average of the entire nebula while the visual measurements usually refer to only a small part of the nebula. For one of the nebulae under consideration, NGC 5882, 
Table 18. Ionic concentrations and chemical abundances in NGC 5882. Wavelength in Angstrom for all values of $\lambda$ above 1000, otherwise in $\mu \mathrm{m}$.

\begin{tabular}{lccccc}
\hline \hline Ion & $\lambda$ & Intens./H $\beta$ & $N_{\text {ion }} / N_{\mathrm{p}}$ & ICF & $N_{\text {el. } /} / N_{\mathrm{p}}$ \\
\hline $\mathrm{He}^{+}$ & 5875 & 16. & 0.105 & & \\
$\mathrm{He}^{+}$ & 4471 & 5.5 & 0.105 & & \\
$\mathrm{He}^{++}$ & 4686 & 3.5 & 0.003 & 1 & 0.108 \\
$\mathrm{C}^{++}$ & 1909 & 35.8 & $1.49(-4)$ & 1.5 & $2.2(-4)$ \\
$\mathrm{N}^{+}$ & 6584 & 13.5 & $3.1(-6)$ & & \\
$\mathrm{N}^{++}$ & 1750 & 4.1 & $9.3(-5)$ & & \\
$\mathrm{N}^{++}$ & 57 & 22.8 & $1.25(-4)$ & 1.3 & $1.6(-4)$ \\
$\mathrm{O}^{+}$ & 3727 & 14.9 & $1.1(-5)$ & & \\
$\mathrm{O}^{++}$ & 5007 & 1050. & $4.62(-4)$ & & \\
$\mathrm{O}^{++}$ & 51.9 & 145. & $4.8(-4)$ & & \\
$\mathrm{O}^{+3}$ & 25.8 & 7.7 & $2.6(-6)$ & 1 & $4.8(-4)$ \\
$\mathrm{Ne}^{+}$ & 12.8 & $\leq 17$. & $\leq 3 .(-5)$ & & \\
$\mathrm{Ne}^{++}$ & 15.5 & $212 .$, & $1.43(-4)$ & 1 & $1.5(-4)$ \\
$\mathrm{S}^{+}$ & 6731 & 1.85 & $1.2(-7)$ & & \\
$\mathrm{S}^{++}$ & 18.7 & 31.0 & $3.54(-6)$ & & \\
$\mathrm{S}^{++}$ & 6312 & 1.2 & $3.4(-6)$ & & \\
$\mathrm{S}^{++}$ & 9532 & 64.5 & $4.0(-6)$ & & \\
$\mathrm{S}^{+3}$ & 10.5 & 168. & $8.8(-6)$ & 1 & $1.3(-5)$ \\
$\mathrm{Ar}^{++}$ & 8.99 & 15. & $1.55(-6)$ & & \\
$\mathrm{Ar}^{++}$ & 7136 & 15.0 & $1.52(-6)$ & & \\
$\mathrm{Ar}^{+3}$ & 4740 & 3.0 & $1.05(-6)$ & 1.1 & $2.9(-6)$ \\
$\mathrm{Cl}^{++}$ & 5538 & 0.51 & $8.1(-8)$ & & \\
$\mathrm{Cl}^{+3}$ & 8046 & 0.62 & $6.6(-8)$ & 1.2 & $1.8(-7)$ \\
$\mathrm{Si}^{++}$ & 1892 & 2.2 & $1.9(-6)$ & $2:$ & $3.8(-6):$ \\
$\mathrm{C}^{++}$ & 4267 & 0.35 & $3.4(-4)$ & & \\
\hline & & & & &
\end{tabular}

Intensities given with respect to $\mathrm{H} \beta=100$.

measurements were taken in the visual averaged over the entire nebula by Tsamis et al. (2003) and are shown in Table 6 . As the table shows, these measurements are in good agreement with the results found by measuring smaller regions of the same nebula. Although the average spectrum is not available for the other two nebulae it is likely that it will not be too different than an average of the individual measurements. This is both because a line-of-sight averaging always is made, and the area measured is relatively large.

An error may occur in correcting for the extinction, either because the extinction is incorrect or the average reddening law is not applicable. We have tried to minimize this possibility by making use of known atomic constants to relate the various parts of the spectrum. Thus the ratio of the infrared spectrum to the visible spectrum is fixed by the ratio of $\mathrm{Br} \alpha$ to $\mathrm{H} \beta$ which is almost an atomic constant. In addition, much use is made of the far infrared lines where extinction does not play a role.

In this connection it is found that the extinction determined from the ratio of the radio continuum emission to the $\mathrm{H} \beta$ flux sometimes differs from the extinction determined from the Balmer decrement. In addition the extinction determined by various authors from the Balmer decrement for the same
Table 19. Comparison of abundances in IC 418.

\begin{tabular}{lrrrrrr}
\hline \hline Elem. & Pres. & Hy (1) & Hy (2) & HKB (3) & H (4) & S (5) \\
\hline $\mathrm{He}$ & $\geq 0.072$ & $\geq 0.07$ & $\geq 0.07$ & 0.09 & 0.098 \\
$\mathrm{C}(-4)$ & 6.2 & 2.7 & 3.0 & 2.2 & 7.1 & 2.5 \\
$\mathrm{~N}(-4)$ & 0.95 & 0.83 & 0.70 & 0.86 & 0.84 \\
$\mathrm{O}(-4)$ & 3.5 & 2.1 & 1.8 & 1.53 & 4.9 \\
$\mathrm{Ne}(-4)$ & 0.88 & 0.61 & 0.30 & 0.096 & 1.2 \\
$\mathrm{~S}(-6)$ & 4.4 & 2.7 & 2.5 & & 16. \\
$\mathrm{Ar}(-6)$ & 1.8 & 1.9 & 0.55 & & 2.5 \\
$\mathrm{Cl}(-7)$ & 1.2 & 0.77 & 1.0 & & 1.9 \\
\hline
\end{tabular}

(1) Hyung et al. (1994), ICF; (2) Hyung et al. (1994, model); (3) Henry et al. (2000), (4) Harrington et al. (1980, (5) Solar: Anders \& Grevesse (1989); Allende Prieto et al. (2001, 2002); Grevesse \& Sauval (1998).

Table 20. Comparison of abundances in IC 2165.

\begin{tabular}{lrrrrr}
\hline \hline Elem. & Present & Hy (1) & Hy (2) & KHM (3) & Solar (4) \\
\hline $\mathrm{He}$ & 0.104 & 0.107 & 0.105 & 0.09 & 0.098 \\
$\mathrm{C}(-4)$ & 4.8 & 4.28 & 4.1 & & 2.5 \\
$\mathrm{~N}(-4)$ & 0.73 & 0.63 & 0.80 & 1.33 & 0.84 \\
$\mathrm{O}(-4)$ & 2.5 & 1.42 & 2.0 & 3.11 & 4.9 \\
$\mathrm{Ne}(-4)$ & 0.57 & 0.63 & 0.50 & 0.69 & 1.2 \\
$\mathrm{Mg}(-6)$ & 12. & 2.3 & & & 3.8 \\
$\mathrm{Si}(-6)$ & 3.0 & 1.78 & 3.0 & & 3.6 \\
$\mathrm{~S}(-6)$ & 4.5 & 2.36 & 2.8 & 2.7 & 16. \\
$\mathrm{Ar}(-6)$ & 1.2 & 1.23 & 1.0 & 1.6 & 2.5 \\
$\mathrm{Cl}(-7)$ & 1.1 & 0.88 & 0.90 & 0.67 & 1.9 \\
$\mathrm{~K}(-8)$ & 6.2 & 7.0 & 8.0 & & 13. \\
\hline
\end{tabular}

(1) Hyung (1994), ICF; (2) Hyung (1994), model; (3) Kwitter et al. (2003), (4) Solar: Anders \& Grevesse (1989); Allende Prieto et al. (2001, 2002); Grevesse \& Sauval (1998).

nebula sometimes differ. At first attempted to redo the extinction correction so that consistently the radio: $\mathrm{H} \beta$ extinction was consistently used. We found that this led to line ratios which were inconsistent, not only for the Balmer decrement but for other lines as well. The most consistent results were obtained by using the line ratios determined by the individual authors using their own Balmer decrement extinction correction. This probably is caused by incorrect wavelength calibrations.

A further error is introduced by the correction for unseen stages of ionization. This varies with the element, but is usually small because very many ionization stages are observed. Thus for neon all but neutral neon is observed, so that the error is negligible. This is also usually true for argon, oxygen and nitrogen, and sometimes for sulfur. There is also an error due to an incorrect determination of the electron temperature. This is very small for ions represented by infrared lines, so that the abundances of neon, argon and sulfur will not be affected. The abundance of carbon is more sensitive to the temperature 
Table 21. Comparison of abundances in NGC 5882.

\begin{tabular}{lrrrrr}
\hline \hline Elem. & Present & GM (1) & KHM (2) & TS (3) & Solar (4) \\
\hline $\mathrm{He}$ & 0.108 & 0.111 & 0.12 & 0.109 & 0.098 \\
$\mathrm{C}(-4)$ & 2.2 & & & 1.5 & 2.5 \\
$\mathrm{~N}(-4)$ & 1.6 & 1.4 & 1.8 & 1.5 & 0.84 \\
$\mathrm{O}(-4)$ & 4.8 & 4.9 & 5.5 & 4.9 & 4.9 \\
$\mathrm{Ne}(-4)$ & 1.5 & & 1.5 & 1.4 & 1.2 \\
$\mathrm{~S}(-6)$ & 13. & 7.0 & 9.0 & 8.4 & 16. \\
$\mathrm{Ar}(-6)$ & 2.9 & 3.1 & 2.8 & 2.0 & 2.5 \\
$\mathrm{Cl}(-7)$ & 1.8 & $\geq 0.8$ & 1.7 & 1.8 & 1.9 \\
\hline
\end{tabular}

(1) Guerrero \& Manchado (1999); (2) Kwitter et al. (2003; (3) Tsamis et al. (2003); (4) Solar: Anders \& Grevesse (1989); Allende Prieto et al. (2001, 2002); Grevesse \& Sauval (1998).

however, and the uncertainty for carbon is higher than for the other elements, which are probably correct to within $20 \%$.

\subsection{Recombination line abundances of carbon}

The $\mathrm{C}^{++}$population can be obtained from the recombination line $\lambda 4267 \AA$ as well as from the collisionally excited line at $\lambda 1909 \AA$. The advantage of the recombination line is that it is not sensitive to the electron temperature, and is in the visual spectrum as well. It has the disadvantage that it is quite faint and thus difficult to measure accurately. It has been used for at least 30 years, and has been found to give higher $\mathrm{C}^{++}$populations than the collisional line. The reason for this is not clear (e.g. see the discussion of Liu et al. 2000).

In IC 418 the $\mathrm{C}^{++}$recombination line $\lambda 4267 \AA$ yields an abundance $\mathrm{C}^{++} / \mathrm{H}$ of $4.13 \times 10^{-4}$. We have also obtained an abundance of $4.44 \times 10^{-4}$ from the $\lambda 6578 \AA$ line and an abundance of $7.04 \times 10^{-4}$ from the $\lambda 1761 \AA$ line, using the effective recombination coefficients given by Davey et al. (2000) for their Case B, which refers to a nebula which is optically thick for the resonance transition. These values are somewhat higher than the value of $2.15 \times 10^{-4}$ obtained from the collisionally excited line. For IC 2165 the $\lambda 4267 \AA$ yields an abundance of $3.64 \times 10^{-4}$, the $\lambda 6578 \AA$ line an abundance of $1.41 \times 10^{-4}$. This difference could be due to the difficulty of accurately measuring weak lines, although the difference is rather large. The $\lambda 1761 \AA$ line gives a much higher abundance: $\mathrm{C}^{++} / \mathrm{H}=2.33 \times 10^{-3}$. This is for Case $\mathrm{B}$, in which the nebula is optically thick for the resonance transition. If the nebula is thin (Case A) for the resonance transition the abundance from the $\lambda 1761 \AA$ would be increased so that this cannot solve the problem.

For NGC 5882 only the $\lambda 4267 \AA$ line has been measured. It yields a value of $\mathrm{C}^{++} / \mathrm{H}=3.4 \times 10^{-4}$ which is in slightly higher than the value obtained from the collisional line.

To summarize, the $\lambda 4267 \AA$ and $\lambda 6578 \AA$ lines give the same value of $\mathrm{C}^{++} / \mathrm{H}$ as the collisional lines at $\lambda 1909 \AA$ to within about a factor of two for all three nebulae, and the value is not systematically higher or lower. The $\lambda 1761 \AA$ line gives a much higher value of $\mathrm{C}^{++} / \mathrm{H}$ for the two cases it is measured.
Table 22. Central star temperatures

\begin{tabular}{lcccc}
\hline \hline Nebula & $T_{\mathrm{z}}(\mathrm{H})$ & $T_{\mathrm{z}}(\mathrm{HeII})$ & $T_{\mathrm{EB}}$ & Temp. \\
\hline IC 418 & 34000 & & 30000 & 33000 \\
NGC 5882 & 50000 & 64000 & 70000 & 67000 \\
IC 2165 & 132000 & 135000 & 120000 & 134000 \\
\hline
\end{tabular}

This probably indicates that the formation of this recombination line (and perhaps other recombination lines) is not completely understood.

\section{The central star}

\subsection{Stellar temperature}

Enough information is available to compute both the Zanstra temperature and the Energy Balance temperature of the central star. The Zanstra temperature requires the knowledge of the stellar apparent magnitude, the extinction and the $\mathrm{H} \beta$ flux. The last two quantities have already been given in Sect. 3 . The apparent magnitude $V$ is 10.17 for IC 418 (Shaw \& Kaler 1989), $V=13.43$ for NGC 5882 (Shaw \& Kaler 1989), and $V=17.47$ (Wolff et al. 2000). Assuming that the star radiates as a blackbody the hydrogen Zanstra temperature $\left(T_{\mathrm{Z}}(\mathrm{H})\right)$ and the ionized helium Zanstra temperature are given in Cols. 2 and 3 of Table 22. The Energy Balance temperature requires the knowledge of the ratio of the "forbidden" line intensities to $\mathrm{H} \beta$. This value is found by summing the intensities given in Sect. 4, and is 6.9 for IC 418, 23.0 for NGC 5882 and 44.9 for IC 2165. To convert these values to a stellar temperature, the formulation of Preite-Martinez \& Pottasch (1983) is used, assuming blackbody radiation from the central star. The average value of Case II (the nebula is optically thin for radiation which will ionize hydrogen but optically thick for ionized helium radiation) and Case III (optically thick for hydrogen ionizing radiation as well) for the energy balance temperature $\left(T_{\mathrm{EB}}\right)$ is given in Col. 4 of the table. Finally an average stellar temperature is given in Col. 5 .

\subsection{Radius and luminosity}

The stellar radius and luminosity are dependent on the distance of the nebulae which is difficult to obtain accurately. For this discussion we will use the distances cited above: $d=1 \mathrm{kpc}$ (IC 418), $d=1 \mathrm{kpc}$ (NGC 5882) and $d=3 \mathrm{kpc}$ (IC 2165). Similar values are cited in the literature especially as "individual distances". These values have an uncertainty which could be larger than $40 \%$. The distance, combined with the magnitude of the star, leads to the stellar radii which are shown in Table 23. Once the radius is known the gravity may be computed assuming that the star has a mass of 0.6 solar mass. The radius and the temperature give the luminosity shown in Table 23 .

It is also possible to obtain the stellar luminosity from the nebular $\mathrm{H} \beta$ luminosity, since there is a direct relationship between the number of ionizing photons and the number of $\mathrm{H} \beta$ photons, in the case in which the nebula absorbs all the ionizing photons emitted by the star. A mathematical 
Table 23. Central star temperatures

\begin{tabular}{lcccc}
\hline \hline Nebula & $\begin{array}{c}\text { Distance } \\
\mathrm{kpc}\end{array}$ & $\begin{array}{c}\text { Radius } \\
R / R_{\odot}\end{array}$ & $\begin{array}{c}\text { Gravity } \\
g / g_{\odot}\end{array}$ & $\begin{array}{c}\text { Luminosity } \\
L / L_{\odot}\end{array}$ \\
\hline IC 418 & 1 & 1.43 & 0.294 & 2550. \\
NGC 5882 & 1 & 0.227 & 12.3 & 830. \\
IC 2165 & 3 & 0.0774 & 101. & 1610. \\
\hline
\end{tabular}

formulation of this can be found in Pottasch \& Acker (1989). It yields the following luminosities: $L / L_{\odot}=3900$ (IC 418), $L / L_{\odot}=430$ (NGC 5882), and $L / L_{\odot}=190$ (IC 2165). These values differ somewhat from the values given in Table 23 . Especially the large difference for IC 2165 probably indicates that this nebula does not absorb all the ionizing photons, but allows a large number to escape from the nebula. On the other hand, IC 418 appears to be optically thick to ionizing photons. This comparison does not give any information about the distance, since both formulations have the same distance dependance.

\section{Discussion and conclusions}

The rather low luminosity of the central star of these nebulae, although quite uncertain, leads to the expectation that the initial mass of the star was low so that only the first dredge-up (and possibly the third dredge-up) took place. This seems in general agreement with the abundance determinations. Nitrogen has not been increased above the solar value in IC 418 and IC 2165 and there is only an increase of about a factor of two in NGC 5882. This, coupled with the general similarity of the abundance in these nebulae with the solar abundance leads to the conclusion that the second dredge-up did not occur. As a consequence the central star masses are less than about 3 solar masses.

The carbon abundance however, has definitely increased in both IC 418 and IC 2165, where it is now almost twice the oxygen abundance. This suggests that a "third dredge-up" took place in these two central stars to produce the observed overabundance of carbon. If it did, it did not increase the helium abundance, which in IC 2165 is not greater than in NGC 5882.

The role of the intensity of the $\mathrm{C}^{++}$recombination line intensities is discussed. It appears difficult to explain the ratios of $\lambda 4267 \AA / \lambda 1761 \AA$ in both nebulae with the same recombination line theory. The theory may have to be reconsidered.

Acknowledgements. We thank Dr. J. Condon for rereducing the PMN radio survey data for NGC 5882.

\section{References}

Allende Prieto, C., Lambert, D. L., \& Asplund, M. 2001, ApJ, 556, L63

Allende Prieto, C., \& Prieto, D. L. 2002, ApJ, 573, L137

Anders, E., \& Grevesse, N. 1989, Geochem. Cosmo., 53, 197

Becker, R. H., White, R. L., \& Edwards, A. L. 1991, ApJS, 75, 1

Benjamin, R. A., Skillman, E. D., \& Smits, D. P. 1999, ApJ, 514, 307

Bernard Salas, J., Pottasch, S. R., Beintema, D. A., \& Wesselius, P. R. 2001, A\&A, 367, 949
Bernard-Salas, J., Pottasch, S. R., Feibelman, W. A., \& Wesselius, P. R. 2002, A\&A, submitted

Bianchi, L., \& Grewing, M. 1987, A\&A, 181, 85

Cahn, J. H., Kaler, J. B., \& Stanghellini, L. 1992, A\&AS, 94, 399

Carrasco, L., Serrano, A., \& Costero, R. 1983, RMxAA, 8, 187

Ciardullo, R., Bond, H. E., Sipior, M. S., et al. 1999, AJ, 118, 488

Condon, J. J., \& Kaplan, D. L. 1998, ApJS, 117, 361

Corradi, R. L. M., Schonberner, D., Steffen, M., et al. 2003, MNRAS, 340,417

Davey, A. R., Storey, P. J., \& Kisielius, R. 2000, A\&AS, 142, 85

Feibelman, W. A. 1999, ApJ, 514, 296

Fluks, M. A., Plez, B., de Winter, D., et al. 1994, A\&AS, 105, 311

Gregory, P. C., \& Condon, J. J. 1991, ApJS, 75, 1011

Gregory, P. C., Vavasour, J. D., Scott, W. K., et al., 1994, ApJS, 90, 173

Grevesse, N., \& Sauval, A. J. 1998, Space Sci. Rev., 85, 161

Griffith, M. R., Wright, A. E., Burke, B. F., \& Ekers, R. D. 1994, ApJS, 90, 179

Guerrero, M. A., \& Manchado, A. 1999, ApJ, 522, 378

Gutierrez-Moreno, A., Moreno, H., \& Cortes, G. 1985, PASP, 98, 488

Gutierrez-Moreno, A., \& Moreno, H. 1988, PASP, 100, 1497

Harrington, J. P., Lutz, J. H., Seaton, M. J., et al. 1980, MNRAS, 191, 13

Henry, R. B. C., Kwitter, K. B., \& Bates, J. A. 2000, ApJ, 531, 928

Hippelein, H., \& Munch, G. 1981, A\&A, 95, 100

Hummer, D. G., \& Storey, P. J. 1987, MNRAS, 224, 801

Hyung, S. 1994, ApJS, 90, 119

Hyung, S., Aller, L. H., \& Feibelman, W. A. 1994, PASP, 106, 745

Johansson, S. 1988, ApJ, 327, L85

Keenan, F. P., Aller, L. H., Bell, K. L., et al. 1998, MNRAS, 295, 683

Keenan, F. P., Aller, L. H., Bell, K. L., et al. 1999, MNRAS, 304, 27

Kingsburgh, R. L., \& Barlow, M. J. 1994, MNRAS, 271, 257

Kwitter, K. B., Henry, R. B. C., \& Milingo, J. B. 2003, PASP, 115, 80

Liu, X.-W., Storey, P. J., Barlow, M. J., et al. 2000, MNRAS, 312, 585

Liu, X.-W., Barlow, M. J., Cohen, M., et al. 2001, MNRAS, 323, 343

Meaburn, J., Lopez, J. A., Bryce, M., \& Mellema, G. 1996, A\&A, 307, 579

Milne, D. K. 1979, A\&AS, 36, 27

Milne, D. K., \& Aller, L. H. 1982, A\&AS, 50, 209

Pacheco, J. A. de Freitas, Maciel, W. J., Costa, R. D. D., et al. 1991, A\&A, 250, 159

Pottasch, S. R., \& Acker, A. 1989, A\&A, 221, 123

Pottasch, S. R., \& Beintema, D. A. 1999, A\&A, 347, 974

Pottasch, S. R., Wesselius, P. R., Wu, C. C., et al. 1977, A\&A, 54, 435

Pottasch, S. R., Beintema, D. A., \& Feibelman, W. A. 2000, A\&A, 363, 767

Pottasch, S. R., Beintema, D. A., Bernard Salas, J., \& Feibelman, W. A. 2001, A\&A, 380, 684

Pottasch, S. R., Preite-Martinez, A., Olnon, F. M., et al. 1986, A\&A, 161,363

Pottasch, S. R., Beintema, D. A., Bernard Salas, J., et al. 2002, A\&A, 393, 285

Preite-Martinez, A., \& Pottasch, S. R. 1983, A\&A, 126, 31

Rowlands, N., Houck, J. R. Skrutskie, M. F., et al. 1993, PASP, 105, 1287

Shaw, R. A., \& Kaler, J. B. 1989, ApJS, 69, 495

Taylor, A. R., Gussie, G. T., \& Goss, W. M. 1989, ApJ, 340, 932

Torres-Peimbert, S., Peimbert, M., \& Daltabuit, E. 1980, ApJ, 238, 133

Tsamis, Y. G., Barlow, M. J., Liu, X.-W., et al. 2003, MNRAS, 345, 186

Willner, S. P., Jones, B., Puetter, R. C., et al. 1979, ApJ, 234, 496

Wolff, M. J., Code, A. D., \& Groth, E. J. 2000, AJ, 119, 302

Wright, A. E., Griffith, M. R., Burke, B. F., \& Ekers, R. D. 1994, ApJS, 91, 111 